\title{
COGNITIVE AND MOTOR DEVELOPMENT IN PRESCHOOL AND SCHOOL-AGED CHILDREN AFTER NEONATAL ARTERIAL SWITCH OPERATION
}

Hedwig H. Hövels-Gürich, MD Marie-Christine Seghaye, $\mathrm{MD}^{\mathrm{a}}$ Sabine Däbritz, MD ${ }^{\mathrm{b}}$

Bruno J. Messmer, MD ${ }^{\mathrm{b}}$

Götz von Bernuth, MD ${ }^{\mathrm{a}}$
Objective: The developmental status of children beyond 3 years of age after the neonatal arterial switch operation has not yet been systematically evaluated and is the topic of the present work. Methods: Seventy-seven unselected children operated on as neonates with combined deep hypothermic circulatory arrest and low-flow cardiopulmonary bypass were examined at an age of 3.2 to 9.4 years ( $5.4 \pm 1.6$ years, mean \pm standard deviation). Clinical neurologic status, standard scores of intelligence, acquired abilities and vocabulary, and standardized tests on gross motor and fine motor functions were carried out, and the results were related to preoperative, perioperative, and postoperative status and management. Results: Neurologic impairment was more frequent $(9.1 \%)$ than in the normal population. Intelligence was not different in these patients compared with normal children $(p=0.11$ ), but motor function, vocabulary, and acquired abilities were poorer. Reduced intelligence was found in $9.1 \%$, fine motor dysfunction in $22.1 \%$, and gross motor dysfunction in $23.4 \%$ of the children. Intelligence was weakly but significantly inversely related to the duration of bypass (Spearman correlation coefficient $-0.25, p=0.03$ ) and tended to be inversely related to the duration of circulatory arrest $(-0.21, p=0.07)$, but not to core cooling time on bypass or degree of hypothermia. Gross motor function, vocabulary, and acquired abilities were not significantly related to any of the perioperative parameters considered. No correlation was found between the test results and the variables perinatal asphyxia, perioperative and postoperative cardiocirculatory insufficiency, resuscitation events, and plexal or intraventricular cerebral hemorrhage. Conclusions: The neonatal arterial switch operation with combined circulatory arrest and low-flow bypass in our experience is associated with neurologic as well as fine and gross motor impairment but appears to be well tolerated concerning cognitive functions as based on formal intelligence testing. ( $J$ Thorac Cardiovasc Surg 1997;114:578-85)
A $s$ advances in pediatric cardiovascular surgery over the past 35 years ${ }^{1,2}$ have allowed the repair of congenital heart defects at increasingly younger ages, as well as a dramatic reduction of mortality

From the Departments of Pediatric Cardiology ${ }^{\mathrm{a}}$ and Cardiothoracic Surgery, ${ }^{b}$ RWTH Aachen, Aachen, Germany.

Supported by grants of "Land Nordrhein-Westfalen" and "Bundesverband Herzkrankes Kind e.V.," Germany.

Received for publication Nov. 7, 1996; revisions requested Jan. 2, 1997; revisions received May 5, 1997; accepted for publication May 6, 1997.

Address for reprints: H. H. Hövels-Gürich, MD, Department of Pediatric Cardiology, RWTH Aachen, Pauwelsstr. 30, D52057 Aachen, Germany.

Copyright (C 1997 by Mosby-Year Book, Inc.

$0022-5223 / 97 \$ 5.00+0 \quad \mathbf{1 2 / 1 / 8 3 0 6 6}$ and cardiac morbidity, ${ }^{3}$ neurologic dysfunction and developmental sequelae after pediatric cardiac operations have become an important area of concern. Perioperative events, including the support techniques cardiopulmonary bypass (CPB) and deep hypothermic circulatory arrest (DHCA) in combination with preoperative and postoperative factors, are assumed to influence later developmental outcome in a complex manner., 5

Neonates with transposition of the great arteries undergoing the arterial switch operation (ASO) comprise a group receiving a homogeneous treatment regimen. This facilitates evaluation of later neurologic and developmental functions with regard to preoperative, perioperative, and postoperative events. Recent investigations $s^{4,6-8}$ have related 
mainly to patients younger than 2 years of age. Less information is available concerning children of preschool and school age. Assessments in older children, however, should reveal more clearly differences in neurologic and developmental sequelae compared with normal children. ${ }^{8}$

The purpose of our study was to evaluate neurologic, cognitive, and motor development in children 3 to 9 years after neonatal ASO for transposition of the great arteries and to compare their development with that of normal children. Information should be obtained as to which factors in preoperative, perioperative, and postoperative management influence later outcome and to what degree neonatal surgery performed with DHCA and with CPB by itself may cause neurologic and developmental impairment.

\section{Methods}

Patient population. Between March 1986 and February 1992, 96 newborn infants with transposition of the great arteries underwent the ASO. Total mortality was $7.3 \%$, but it was only $5.4 \%$ in the 56 patients operated on from 1990 to 1992.

This study was designed as a case series with published controls and prognostic factor analyses. The study group comprised 77 unselected children $(86.5 \%$ of the survivors), $71.4 \%$ of whom were male and $28.6 \%$ female. Interviews with their parents revealed a middle-class population without signs of important socioeconomic differences between the families. The children who did not participate in the study were not different from the study patients concerning their socioeconomic background; participation was determined mainly by the distance of the family's residence from our institution. Telephone calls with the parents of nonparticipating patients, as well as systematically collected written reports from their treating pediatric cardiologists since infancy, suggested that their neurodevelopmental outcome was no worse than that of the participants in the study.

Birth weight was $3.49 \pm 0.5 \mathrm{~kg}$ (mean \pm standard deviation [SD]). Of these patients, $71.4 \%$ had a simple transposition of the great arteries, $19.5 \%$ had, in addition, an unimportant ventricular septal defect, $3.9 \%$ had a ventricular septal defect closed during the ASO, and 5.2\% had a coarctation of the aorta corrected at a later date. Among these neonates, $84.4 \%$ had undergone atrial balloon septostomy, and $97.4 \%$ had been treated with prostaglandin $\mathrm{E}_{1}$ before the operation.

Ages at the time of the neurologic and developmental examination ranged from 3.2 to 9.4 years $(5.4 \pm 1.6$ years, mean $\pm \mathrm{SD}$ ).

Surgical management and perfusion methods. ASO was performed in our institution by two surgeons according to a standardized technique based on the Lecompte modification with DHCA and combined low-flow CPB. After introduction of general anesthesia, core cooling on CPB was instituted to reach an esophageal temperature of $14^{\circ}$ to $17^{\circ} \mathrm{C}\left(15.1^{\circ} \pm 1.0^{\circ} \mathrm{C}\right)$. The temperature of the
Table I. Preoperative, perioperative and postoperative course-Risk factors for development outcome

\begin{tabular}{ll}
\hline \multicolumn{1}{c}{ Risk Factor } & Definition \\
\hline $\begin{array}{l}\text { Duration of DHCA } \\
\text { Duration of CPB }\end{array}$ & - \\
Duration of core cooling & \\
on CPB & \\
Temperature at initiation & \\
of DHCA & Apgar score $<7$ after 5 minutes \\
Perinatal asphyxia & Low cardiac output* despite ade- \\
Perioperative and postop- & quate filling pressures and ino- \\
erative cardiocirculatory & tropic and vasodilatory therapy \\
insufficiency & Necessity of pharmacologic and/or \\
Perioperative and postop- & mechanical resuscitation \\
crative resuscitation & \\
events & Evaluation by means of preopera- \\
Postoperative plexal or & tive and postoperative cranial \\
intraventricular cerebral & ultrasonographic examination in \\
hemorrhage & all patients
\end{tabular}

${ }^{*}$ Low cardiac output $=$ clinically estimated by means of arterial pressure (target value for mean pressure $45 \mathrm{~mm} \mathrm{Hg}$ ), central venous pressure (target value 5 to $7 \mathrm{~mm} \mathrm{Hg}$ ), diuresis (target value $>1.5 \mathrm{~mL} / \mathrm{kg}$ of body weight per hour), capillary refill time, and skin temperature.

priming fluid was $20^{\circ}$ to $22^{\circ} \mathrm{C}$. Priming solution consisted of a pH-balanced crystalloid solution containing $5 \%$ glucose and packed red cells to achieve a hematocrit value of the circulating volume of 0.25 . The duration of core cooling ranged from 7 to 20 minutes $(10.6 \pm 2.6$ minutes). Duration of DHCA ranged from 51 to 70 minutes $(60.1 \pm$ 4.5 minutes), and total $\mathrm{CPB}$ including core rewarming time comprised 41 to 116 minutes ( $63.7 \pm 15.2$ minutes). Low-flow perfusion rate was $0.7 \mathrm{~L} / \mathrm{m}^{2}$ body surface area per minute. During $\mathrm{CPB}$, the $\mathrm{pH}$-stat method was used, ${ }^{9}, 10$ correcting arterial carbon dioxide tension to the patient's hypothermic temperature to maintain a $\mathrm{pH}$ value of 7.40. At the beginning of CPB, phentolamine $(0.1$ $\mathrm{mg} / \mathrm{kg}$ ) and, since 1990, sodium nitroprusside was added for vasodilatation, and dexamethasone $\left(3 \mathrm{mg} / \mathrm{m}^{2}\right.$ body surface area) was given to prevent cerebral edema.

The age at repair for the study group ranged from 2 to 39 days ( $7.0 \pm 4.6$ days). Two patients were older than 12 days.

Preoperative, perioperative, and postoperative course. The patients' charts were carefully reviewed with respect to perioperative management, as well as preoperative, perioperative, and postoperative complications. For the analysis of the influence of risk factors on later outcome, a list of definite variables, available in all patients, was considered (Table I).

Neurologic examination. Complete clinical neurologic status was evaluated by an examiner experienced in neuropediatric examinations. Results were classified as normal or impaired. Neurologic dysfunction was diagnosed in those patients who had the following abnormalities: cerebral palsy, seizures, ataxia, alteration of muscular tone, microcephaly, or hydrocephalus. 
Table II. Neurologic dysfunction after ASO according to the type

\begin{tabular}{lcc}
\hline \multicolumn{1}{c}{ Type of dysfunction } & No. & $\%$ \\
\hline Dysfunction in total* & 7 & 9.1 \\
Cerebral palsy & 4 & 5.2 \\
Ataxia & 3 & 3.9 \\
Clinical seizures & 2 & 2.6 \\
Alteration of muscular tone & 2 & 2.6 \\
Microcephaly & 1 & 1.3 \\
Hydrocephalus & 1 & 1.3 \\
\hline
\end{tabular}

* More than one type of dysfunction possible in one child.

Developmental testing. All assessments were conducted by the same examiner on two consecutive days in our institution. Some assessments were not performed in all the children because of age limitation, physical disability (c.g., cerebral palsy), or lack of cooperation, as explained in the context.

Quantitative standardized tests. The Kaufman Assessment Battery for Children, ${ }^{11}$ standardized for children 2.5 to 12.5 years of age, consisting of two separate test blocks to evaluate standard scores of intelligence (intelligence quotient) $(n=77)$ as well as standard scores of acquired abilities (learning, knowledge) ( $n=71$, since six children uncooperative), was administered in the whole cohort. The vocabulary test as a subtest of the Kaufman Assessment Battery for Children, limited to children 2.6 to 4.11 years of age, assessing power of memory and expressive skills, was administered in 46 children.

The Kiphard and Schilling Body Coordination Test, ${ }^{12}$ standardized for children 5.0 to 14.11 years of age, assessing standard scores of gross motor function (motor quotient), was administered in 37 children.

The aforementioned tests are normalized for age to have a mean of 100 and an SD of 15. Dysfunction was diagnosed when standard scores were below the simple $\mathrm{SD}(<-1 \mathrm{SD}$, standard scores $<85)$.

Semiquantitative tests. The Denver Developmental Screening Test, ${ }^{13}$ limited to children up to 6 years of age, which evaluates fine motor and gross motor functions, was administered in 56 children. Dysfunction was diagnosed when the test results were reduced more than $50 \%$ related to the child's chronologic age.

Parts of the Frostig Developmental Test of Visual Perception, ${ }^{14}$ limited to children 4 to 10 years of age, examining visual perception and fine motor function, were performed in 33 patients. Dysfunction was diagnosed when the results of the subtests were below the simple SD $(<-1 \mathrm{SD})$.

Developmental test results in the patients were compared with the published results in an age-matched normal German-speaking population on whom the tests or their German adaptations are based. For quantitative standardized tests, the incidence of abnormal results in a normal population is by definition $16 \%(-1 \mathrm{SD}>14 \%>$ -2 SD and $2 \%<-2$ SD).

Statistical analysis. The outcomes included both categoric and continuous variables. Each patient's results of all quantitative and semiquantitative tests applied were summarized in categoric variables-normal function or dysfunction-concerning intelligence, fine motor functions, and gross motor functions. In those instances in which more than one test was used to assess a developmental topic (e.g., gross motor function), dysfunction was diagnosed when dysfunction range was reached in each test.

Statistical analysis of developmental outcome compared with normal children and compared with preoperative, perioperative, and postoperative factors was based on the standardized test scores by means of categoric and continuous variables. Results were expressed by the mean value $\pm \mathrm{SD}$ of the mean or in percentages.

The Fisher exact test was used to analyze categoric variables. Wilcoxon rank-sum tests and correlation analyses (Spearman correlation coefficients) were used to analyze continuous variables. Multivariable analysis by means of a multiple regression model was carried out to define clinically relevant influencing factors associated with later developmental impairment. Variables were selected by a forward selection procedure.

In this study $p$ values less than 0.05 were considered significant and $p$ values between 0.05 and 0.09 were considered to have a tendency toward significance.

\section{Results}

Neurologic examination. Neurologic status was normal in $90.9 \%(n=70)$ and impaired in $9.1 \%$ $(n=7)$ of the children. Percentages of dysfunction according to the type are described in Table II.

Five of the seven children with neurologic abnormalities had had severe preoperative hypoxia, including protracted birth with vacuum extraction and a $\mathrm{pH}$ value of 7.10 in the umbilical venous blood $(n=1)$, protracted birth at home followed by perinatal hypoxia with an Apgar score of 6 after 5 minutes $(n=1)$, severe postnatal asphyxia caused by myocardial insufficiency, pulmonary edema, and reanimation $(n=1)$, postasphyxia syndrome with renal failure and involvement of liver and brain $(n=$ $1)$, and repeated attacks of severe cyanosis caused by intracardiac mixing problems $(n=1)$.

One child needed a ventricular-peritoneal shunt after perioperative intracerebral hemorrhage and permanent hydrocephalus. Another patient had had ataxia and muscular hypertonia since the age of 5 years after acute cerebellar thrombosis of unknown origin (see Fig. 1).

Developmental impairment. Summarizing all test results of each patient in categoric variables, reduced intelligence was found in $9.1 \%: 5.2 \%$ were below the simple SD and $3.9 \%$ were below the double SD. Fine motor dysfunction was found in $22.1 \%$ and gross motor dysfunction in $23.4 \%$. In total, $74 \%$ of all study patients were within normal 


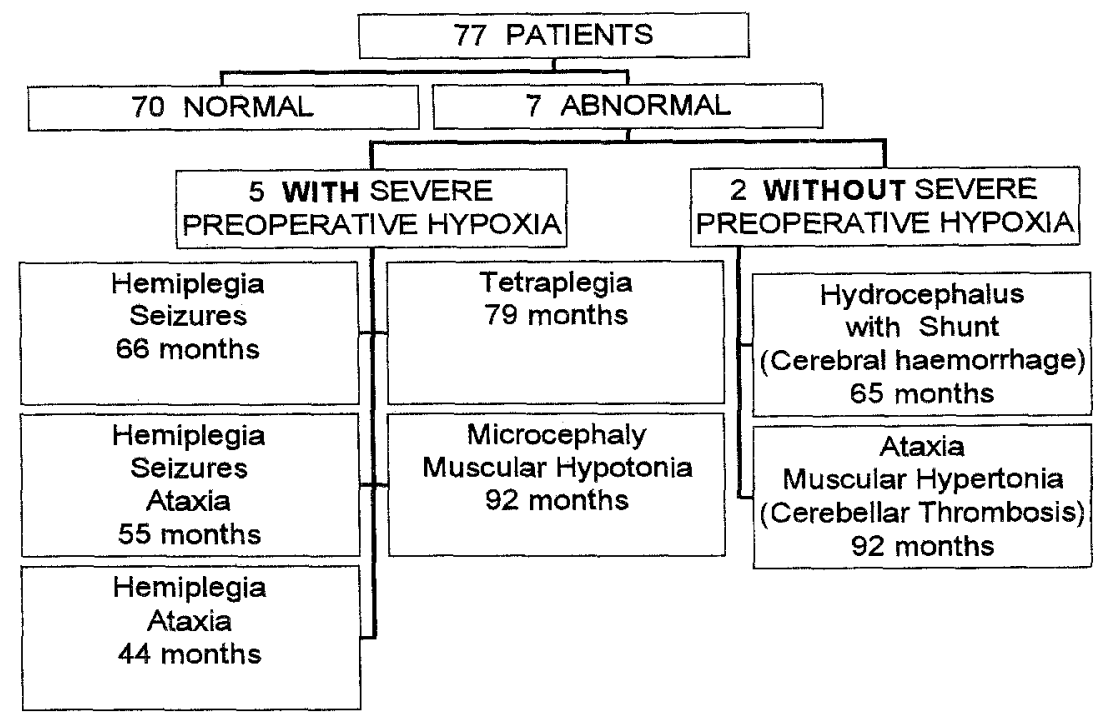

Fig. 1. Diagram of neurologic outcome after ASO showing anamnestic data, age at examination, and type of impairment of the patients.

Table III. Developmental outcome in children after ASO compared with normal children

\begin{tabular}{|c|c|c|c|c|c|}
\hline \multirow[b]{2}{*}{ Developmental test } & \multirow{2}{*}{$\begin{array}{l}\text { Patient } \\
\text { group* }\end{array}$} & \multirow{2}{*}{$\begin{array}{l}\text { Standard score } \\
\pm S D\end{array}$} & \multicolumn{2}{|c|}{ Results (\%) $\dagger$} & \multirow[b]{2}{*}{$p$ Valuet } \\
\hline & & & Normal & Abnormal & \\
\hline \multirow{2}{*}{ Intelligence quotient } & $\mathrm{A}(n=77)$ & $99.1 \pm 14.2$ & 90.9 & 9.1 & 0.11 \\
\hline & $\mathrm{B}(n=70)$ & $100.8 \pm 12.2$ & 94.3 & 5.7 & 0.02 \\
\hline \multirow[t]{2}{*}{ Motor quotient } & $\mathrm{A}(n=37)$ & $88.7 \pm 14.4$ & 67.6 & 32.4 & 0.01 \\
\hline & $\mathrm{B}(n=34)$ & $90.1 \pm 13.5$ & 74.4 & 25.6 & 0.06 \\
\hline \multirow[t]{2}{*}{ Acquired abilities } & $\mathrm{A}(n=71)$ & $97.3 \pm 18.1$ & 70.4 & 29.6 & 0.005 \\
\hline & $\mathrm{B}(n=65)$ & $99.1 \pm 17.5$ & 73.9 & 26.1 & 0.04 \\
\hline \multirow[t]{2}{*}{ Vocabulary } & $\mathrm{A}(n=46)$ & $96.1 \pm 19.5$ & 71.7 & 28.6 & 0.04 \\
\hline & $\mathrm{B}(n=43)$ & $96.9 \pm 19.9$ & 74.4 & 25.6 & 0.10 \\
\hline
\end{tabular}

${ }^{*} A$, All patients; $B$, patients without neurologic damage.

$\dagger$ Normal > $>$ SD; abnormal <-1 SD.

$\subsetneq P$ values (two-tailed) calculated by Fisher's exact tests; normal/abnormal results compared with age-matched normal children (standard score \pm SD $=100 \pm$ $15)$.

limits with regard to cognitive and motor development, as well as neurologic status.

Standardized developmental tests in comparison with normal children. Patients were considered either as a whole group (group A) or as a subgroup comprising patients without neurologic damage (group B) to evaluate whether neurologic dysfunction might be associated with other developmental dysfunctions. The results of the four standardized developmental tests to evaluate intelligence quotient, motor quotient, acquired abilities, and vocabulary are shown in Table III.

Intelligence quotient was not different from normal in patients of group A $(p=0.11)$ and was even significantly better in patients of group B $(p=0.02)$.
Gross motor function (motor quotient) was significantly poorer in patients of group $\mathrm{A}(p=0.01)$ and tended to be poorer in patients of group B $(p=$ $0.06)$. Vocabulary was significantly poorer in patients of group A $(p=0.04)$, but not so in those of group $\mathrm{B}(p=0.10)$.

Acquired abilities were significantly poorer in both patient groups (A: $p=0.005 ; \mathrm{B}: p=0.04$ ).

Influences of preoperative, perioperative, and postoperative parameters on developmental test results. There was a weak, but significantly negative correlation between the intelligence quotient and the duration of CPB (Spearman -0.25, $p=0.03$ ), whereas a tendency toward significance was found between intelligence quotient and the duration of 


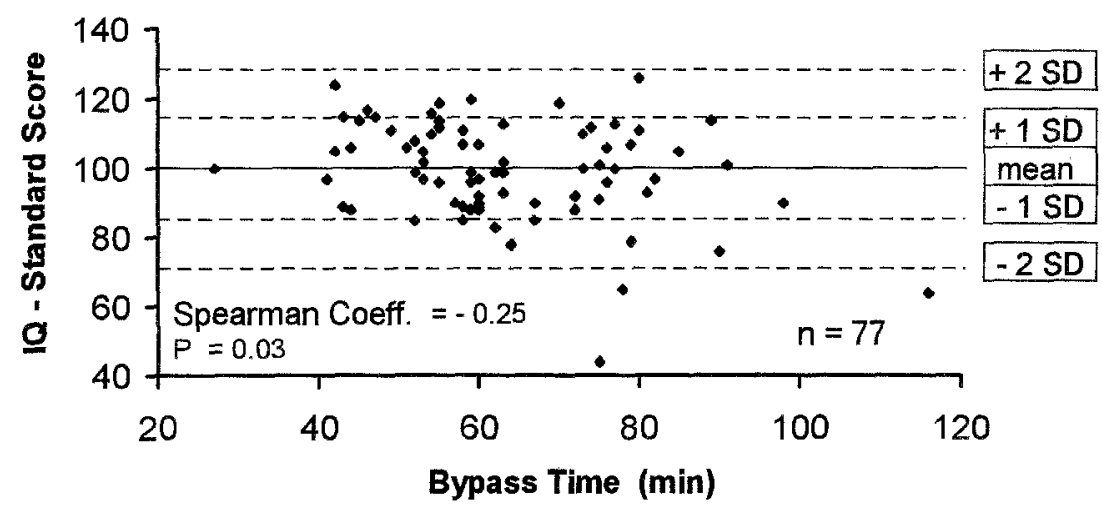

Fig. 2. Plot of the relation between intelligence quotient $(I Q)$ at the time of examination and duration of CPB in 77 patients showing a weak, but significantly negative correlation: Spearman correlation coefficient (Spearman coefficient) $-0.25, p$ value $(P)$ 0.03. The solid line represents the mean value, and the dashed lines represent the simple $( \pm 1 \mathrm{SD})$ and double $( \pm 2 \mathrm{SD}) \mathrm{SD}$, respectively.

Table IV. Correlation analysis between perioperative parameters and developmental test results

\begin{tabular}{|c|c|c|c|c|c|c|c|c|c|}
\hline \multirow{2}{*}{$\begin{array}{l}\text { Perioperative } \\
\text { parameter }\end{array}$} & \multirow[b]{2}{*}{ Mean $\pm S D$} & \multicolumn{2}{|c|}{$\begin{array}{l}\text { Intelligence } \\
\text { quotient }\end{array}$} & \multicolumn{2}{|c|}{$\begin{array}{c}\text { Motor } \\
\text { quotient }\end{array}$} & \multicolumn{2}{|c|}{$\begin{array}{l}\text { Acquired } \\
\text { abilities }\end{array}$} & \multicolumn{2}{|c|}{ Vocabulary } \\
\hline & & $S p^{*}$ & $P t$ & $S p^{*}$ & $P+$ & $S p^{*}$ & $P \dot{t}$ & $S p *$ & $P f$ \\
\hline $\begin{array}{l}\text { Temperature at } \\
\text { initiation of } \\
\text { DHCA }\left({ }^{\circ} \mathrm{C}\right)\end{array}$ & $15.1 \pm 1.0$ & -0.02 & 0.86 & -0.05 & 0.78 & -0.02 & 0.89 & -0.06 & 0.72 \\
\hline $\begin{array}{l}\text { Duration of } \\
\text { core cooling } \\
\text { (min) }\end{array}$ & $10.6 \pm 2.6$ & 0.007 & 0.95 & -0.11 & 0.95 & 0.13 & 0.30 & -0.01 & 0.95 \\
\hline $\begin{array}{l}\text { Duration of } \\
\text { DHCA (min) }\end{array}$ & $60.1 \pm 4.5$ & -0.21 & 0.07 & 0.06 & 0.73 & -0.03 & 0.78 & -0.05 & 0.73 \\
\hline $\begin{array}{l}\text { Duration of } \\
\text { CPB (min) }\end{array}$ & $63.7 \pm 15.2$ & -0.25 & 0.03 & -0.24 & 0.16 & -0.20 & 0.10 & -0.14 & 0.34 \\
\hline
\end{tabular}

Number of patients as shown in Table III. Boldface numbers signify correlations that are statistically significant or have a tendency to significance. * Sp, Spearman correlation coefficient.

$\leftarrow P, P$ values calculated by correlation analysis.

DHCA (Spearman $-0.21, p=0.07$ ). No correlation was found between intelligence quotient and core cooling time or degree of hypothermia. Fig. 2 shows the correlation between intelligence and duration of CPB.

A similar but not statistically significant correlation was calculated between the motor quotient and the duration of CPB (Spearman $-0.24, p=0.16$ ). No correlation was found between motor quotient and the other perioperative parameters. No significant correlation was found between acquired abilities and vocabulary on the one hand and the perioperative parameters on the other hand. Details are given in Table IV.

Multivariable analysis by means of multiple regression was able to confirm a weak but significant correlation of intelligence quotient to duration of
CPB $\left(R^{2}=0.10, p=0.006\right)$ and a tendency toward significance between intelligence quotient and duration of DHCA $\left(R^{2}=0.13, p=0.09\right)$.

No correlation was found between the variables perinatal asphyxia, perioperative and postoperative cardiocirculatory insufficiency, perioperative and postoperative resuscitation events, and plexal or intraventricular cerebral hemorrhage and the test results.

Year of operation and age at testing had no recognizable influence on the test results.

\section{Discussion}

Our data are based on a homogeneous group of neonates with transposition of the great arteries in whom preoperative, perioperative, and postoperative care was conducted according to standardized 
protocols. Developmental follow-up data were prospectively evaluated in a high percentage $(86.5 \%)$ of unselected surviving children.

In univariable and multivariable analyses the outcome data were correlated to retrospectively collected perioperative variables. Compared with normal children, children who underwent ASO had reduced clinical neurologic status: $9 \%$ of the children had neurologic impairment. The incidence of specific abnormalities such as cerebral palsy and focal abnormalities beyond the first year after the operation is similar to that reported in follow-up studies of other study groups. ${ }^{4,6}$ The incidence of neurologic impairment, however, is lower than in a series of 154 patients examined 1 year after neonatal $\mathrm{ASO},{ }^{8}$ in which definite abnormalities were detected in $31 \%$ and possible abnormalities in $3 \%$. This difference may be caused by the fact that in our series with older children definite neurologic dysfunction and unspecific gross motor impairment could be better differentiated from each other.

Intelligence after ASO was not lessened in our patients compared with normal children. The fact that intelligence was significantly better when patients with neurologic damage were excluded suggests that neurologic dysfunction is associated with reduced intelligence. The normal results of intelligence assessment are especially encouraging considering the reduced results after atrial repair of transposition of the great arteries ${ }^{15,16}$ which, of course, include a significant preoperative morbidity. Although no other studies of cognitive function in preschool or school-aged children after neonatal ASO have been published, a recent report on mental developmental scores of 155 patients 1 year after neonatal ASO demonstrated results considerably below population norms. ${ }^{8}$ In contrast, standard scores of intelligence after neonatal ASO were within normal parameters in 24 patients at a mean age of 2.1 years $^{6}$ and in 28 patients, 10 of whom were older than 30 months. ${ }^{4}$

Fine motor dysfunction (22.1\%) and gross motor dysfunction $(23.4 \%)$ in our patients, as judged on the basis of all tests applied, was more prevalent than in the normal population. Reduction of psychomotor development in young children after neonatal ASO was reported in $25 \%,{ }^{6}$ and in a recent study of children 1 year after ASO mean scores for the psychomotor developmental index were $1 \mathrm{SD}$ lower than population norms. ${ }^{8}$ No comparable data on motor development after neonatal ASO in preschool and school-aged children are yet available.
Vocabulary as a part of language and acquired abilities were significantly poorer in our patients than in normal children. Those tests cannot be evaluated free from speech and also from socioeconomic status, which is known to influence developmental outcome after cardiac surgery. ${ }^{17}$

Special examinations concerning the socioeconomic status of the patients had not been performed. In Germany, socioeconomic data are difficult to define by objective means because of restrictive data protection regulations. Interviews with the children's parents, as well as information from their pediatricians, however, revealed no severe social differences between the families and lead to the assumption that the cohort represented an even level of socioeconomic status.

The factors influencing neurologic and developmental outcome after neonatal cardiac surgery are complex and probably involve the interactions of preoperative, perioperative, and postoperative parameters. ${ }^{3,5}$ Although damage to the brain is believed to occur mainly during or immediately after the operation, some impairment can be caused by preoperative illness. ${ }^{7,18,19}$ An association between preoperative hypoxia or acidosis and cognitive function after neonatal ASO had not been found in another study. ${ }^{4}$

In our patients preoperative clinical status, perioperative complications, and postoperative course had not been prospectively evaluated. Thus correlation analysis comparing them with outcome variables must be interpreted with caution. However, the importance of preoperative morbidity is underlined by the fact that five of the seven children in our patient group with neurologic abnormalities had had severe preoperative hypoxemia.

In our study, emphasis is placed on the relation of the carefully documented details of operative support techniques to the outcome variables studied. These techniques, which include $\mathrm{CPB}$, deep hypothermia, and DHCA, have been considered as important causes of cerebral injury. ${ }^{20,21}$

The risks of $\mathrm{CPB}$ comprise the exposure to particulate or gaseous microemboli potentiating the risk of cerebral infarction and increasing the likelihood of developmental impairment, especially of cognitive functions and language. ${ }^{3}$ In our series, longer duration of CPB only marginally increased the risk of intellectual impairment, whereas a significant effect on gross motor dysfunction could not be evaluated, perhaps because too few patients were examined. 
Hypothermia, obtained by surface cooling and core cooling during $\mathrm{CPB}$, causes loss of cerebral autoregulation $^{19,22}$ and may increase the risk of cerebral hypoxia leading to strokes or seizures. Factors influencing cerebral protection during the institution of hypothermia include the degree and duration of cooling and $\mathrm{pH}$ management during the cooling period. Duration of core cooling is reported to be related to intellectual development. ${ }^{4,23}$ In our study group, duration of core cooling ranged from 7 to 20 minutes (mean 10.6 minutes), and we could not demonstrate a statistically significant influence on developmental outcome variables. The degree of hypothermia, quite homogeneous in our series, had no influence on the outcome. The narrow range of both duration and degree of hypothermia, however, might have masked an association to outcome parameters.

Conflicting data exist concerning the management of $\mathrm{pH}$ and carbon dioxide tension during $\mathrm{CPB} .{ }^{3,9,10}$ In the so-called $\mathrm{pH}$-stat method, arterial carbon dioxide tension is corrected to the patient's hypothermic temperature to maintain a $\mathrm{pH}$ value of 7.40 , resulting in cerebral vasodilatation and increased cerebral blood flow, as well as in an increased risk of higher brain pressure and microembolization. In the alpha-stat method, arterial carbon dioxide tension is not corrected to the patient's temperature, resulting in cerebral vasoconstriction, reduced perfusion pressure, and possibly imbalance of brain cooling. In a former study, lower carbon dioxide tension (alphastat) was found to be associated with reduced cognitive outcome compared with the $\mathrm{pH}$-stat method. ${ }^{9}$ In our institution, the pH-stat method was always used.

DHCA with core temperatures of $15^{\circ}$ to $20^{\circ} \mathrm{C}$ and periods of total arrest of 30 minutes are accepted as safe. Times of 45 to 65 minutes, however, are believed by some to eventually cause cerebral damage. $^{19,21,24}$

Recently, in the Boston Circulatory Arrest Study, ${ }^{7,8}$ less good results concerning neurologic and developmental outcome after neonatal ASO were reported in the circulatory arrest group compared with the patients predominantly treated with $\mathrm{CPB}$. A higher incidence of clinical seizures and of ictal activity on the electroencephalogram, as well as greater release of the brain isoenzyme of creatine kinase as an indicator of damage to cerebral tissue shortly after the operation, was found. One year after the operation, a higher risk of delayed motor development and neurologic abnormalities was doc- umented in the circulatory arrest group than in the low-flow CPB group. In some studies, the incidence of developmental deficits was related to the duration of DHCA, ${ }^{25,26}$ whereas in other studies such association was not found. ${ }^{4,20,27-30}$ In our study there was a tendency toward significance between longer duration of DHCA and decreased intelligence. The narrow range of our DHCA times (between 51 and 70 minutes), however, might have masked detection of a more significant correlation.

In conclusion, the present study points out that neurologic impairment, dysfunction in motor and acquired abilities, as well as decreased vocabulary in preschool and school-aged children after neonatal ASO are more frequent than in a normal population, whereas reduced intelligence as based on formal intelligence testing is not. Careful neurologic and developmental assessment in infants and children after neonatal ASO is necessary.

We thank Dipl.Math. V. Schulze, Institute of Biomedical Statistics, RWTH Aachen, Germany, for her support in statistical evaluation. We thank Dipl.Psych. M. Braunschweig, Education Advice Center Aachen, Dr. E. Just, Social-Pediatric Center of the Department of Pediatrics, RWTH Aachen, and Dr. G. Trost-Brinkhues, Public Health Department Aachen, for their advice concerning neurodevelopmental testing.

\section{REFERENCES}

1. Kirklin JW, Dawson B, Devloo RA, Theye RA. Open intracardiac operations: use of circulatory arrest during hypothermia induced by blood cooling. Ann Surg 1961;154: 766-9.

2. Barratt-Boyes BG. Cardiac surgery in neonates and infants. Circulation 1971;44:924-5.

3. Walsh AZ, Morrow DF, Jonas RA. Neurologic and developmental outcomes following pediatric cardiac surgery. Nurs Clin North Am 1995;30:347-64.

4. Bellinger DC, Wernovsky G, Rappaport LA, Mayer JE, Castaneda AR, Farrell DM, et al. Cognitive development of children following early repair of transposition of the great arteries using deep hypothermic circulatory arrest. Pediatrics 1991;87:701-7.

5. Mayer JE. Development, growth and cardiac surgery (editorial). Arch Pediatr Adolesc Med 1991;145:33-4.

6. Mendoza JL, Wilkerson SA, Reese AH. Follow-up of patients who underwent arterial switch repair for transposition of the great arteries. Arch Pediatr Adolesc Med 1991;145: 40-3.

7. Newburger JW, Jonas RA, Wernovsky G, Wypij D, Hickey PR, Kuban KCK, et al. A comparison of the perioperative neurologic effects of hypothermic circulatory arrest versus low-flow cardiopulmonary bypass in infant heart surgery. N Engl J Med 1993;329:1057-64.

8. Bellinger DC, Jonas RA, Rappaport LA, Wypij D, Wernovsky G, Kuban KCK, et al. Developmental and neurologic status of children after heart surgery with hypothermic 
circulatory arrest or low flow cardiopulmonary bypass. N Engl J Med 1995;332:549-55.

9. Jonas RA, Bellinger DC, Rappaport LA, Wernovsky G, Hickey PR, Farrell DM, et al. Relation of pH strategy and developmental outcome after hypothermic circulatory arrest. J Thorac Cardiovasc Surg 1992;106:362-8.

10. Castaneda AR, Jonas RA, Mayer JE, Hanley FL. Cardiopulmonary bypass, hypothermia, and circulatory arrest. In: Cardiac surgery in the neonate and infant. Philadelphia: WB Saunders; 1994. p. 23-39.

11. Kaufman AS, Kaufman NL. Kaufman assessment battery for children $(\mathrm{K}-\mathrm{ABC})$. Circle Pines [MN]: American Guidance Service; 1983. German version: Melchers U, Preuß U. 2nd ed., Lisse, The Netherlands: Swets \& Zeitlinger BV; 1994.

12. Kiphard EJ, Schilling F. Körper-Koordinationstest für Kinder. Weinheim-Basel, Germany: Beltz-Verlag; 1974.

13. Frankenburg WK, Dodds JB. The Denver Developmental Screening Test. J Pediatr 1967;71:181-91. German version: Flehmig I, Hamburg, 1973.

14. Frostig M. Developmental Test of Visual Perception. German version: Lockowandt $O$, Frostigs Entwicklungstest der visuellen Wahrnehmung, 8th ed., Weinheim-Basel, Germany: Beltz-Verlag, 1996.

15. Newburger JW, Silbert AR, Buckley LP, Fyler DC. Cognitive function and age at repair of transposition of the great arteries in children. N Engl J Med 1984;310:1495-9.

16. Hesz N, Clark EB. Cognitive development in transposition of the great vessels. Arch Dis Child 1988;63:198-200.

17. Newburger JW, Wypij D, Kuban KCK, Rappaport LA, Wernovsky G, Hickey $R$, et al. Four year neurodevelopmental status: the Boston circulatory arrest study. Circulation 1996;94(Suppl):I173.

18. Veelken N, Grävinghoff L, Keck EW, Freitag HJ. Improved neurological outcome following early anatomical correction of transposition of the great arteries. Clin Cardiol 1992;15: 275-9.

19. Ferry PC. Neurologic sequelae of open-heart surgery in children. Arch Pediatr Adolesc Med 1990;144:369-73.

20. Wernovsky G, Jonas RA, Hickey PR. Clinical neurologic and developmental studies after cardiac surgery utilizing hypo- thermic circulatory arrest and cardiopulmonary bypass. Cardiol Young 1993;3:308.

21. Jonas RA. Deep hypothermic circulatory arrest: a need for caution. Ann Thorac Surg 1996;61:779-80.

22. Greeley WJ, Ungerleider RM, Smith R, Reves JG. The effects of deep hypothermic cardiopulmonary bypass and total circulatory arrest on cerebral blood flow in infants and children. J Thorac Cardiovasc Surg 1989;97:737-45.

23. Bellinger DC, Wernovsky G, Rappaport LA, Lang P, Hickey $\mathrm{PR}$, Jonas RA, et al. Rapid cooling of infants on cardiopulmonary bypass adversely affects later cognitive function. Circulation 1988;78(Suppl): $\Pi 1358$.

24. Greeley WJ, Kern FH, Ungerleider RM, Boyd JL, Quill T, Smith LR, et al. The effect of hypothermic cardiopulmonary bypass and total circulatory arrest on cerebral metabolism in neonates, infants, and children. $J$ Thorac Cardiovasc Surg 1991;101:783-94.

25. Oates RK, Simpson JM, Turnbull JAB, Cartmill TB. The relationship between intelligence and duration of circulatory arrest with deep hypothermia. J Thorac Cardiovasc Surg 1995;110:786-92.

26. Wright J, Hicks R, Newman D. Deep hypothermic arrest: observations in later development in children. J Thorac Cardiovasc Surg 1979;77:466-9.

27. Eke CC, Gundry SR, Baum MF, Chinnock RE, Razzouk AJ, Bailey LL. Neurologic sequelae of deep hypothermic circulatory arrest in cardiac transplant infants. Ann Thorac Surg 1996;61:783-8.

28. Stevenson J, Stone E, Dillard D, Morgan B. Intellectual development in children subjected to prolonged circulatory arrest during hypothermic open heart surgery in infancy. Circulation 1974;49(Suppl):II54-9.

29. Messmer BJ, Schallberger U, Gattiker R, Senning A. Psychomotor and intellectual development after deep hypothermia and circulatory arrest in early infancy. J Thorac Cardiovase Surg 1976;72:495-502.

30. Clarkson PM, MacArthur BA, Barratt-Boyes BG, Whitlock RM, Neutze JM. Developmental progress after cardiac surgery in infancy using hypothermia and circulatory arrest. Circulation 1980;62:855-61.

\section{Bound volumes available to subscribers}

Bound volumes of The Journal of Thoracic and Cardiovascular Surgery are available to subscribers (only) for the 1997 issues from the Publisher, at a cost of $\$ 110.50$ for domestic, $\$ 139.64$ for Canadian, and $\$ 130.50$ for international subscribers for Vol. 113 (January-June) and Vol. 114 (July-December). Shipping charges are included. Each bound volume contains a subject and author index and all advertising is removed. Copies are shipped within 60 days after publication of the last issue of the volume. The binding is durabie buckram with the Journal name, volume number, and year stamped in gold on the spine. Payment must accompany all orders. Contact Mosby-Year Book, Inc., Subscription Services, 11830 Westline Industrial Drive, St. Louis, Missouri 63146-3318, USA; phone 800-453-4351 or 314-453-4351.

Subscriptions must be in force to qualify. Bound volumes are not available in place of a regular Journal subscription. 